\title{
MPS ve FEM Tabanlı Akışkan-Yapı Etkileşimi Modelinin Çoruh Nehri Üzerindeki Ardıl Baraj-Yıkılma Problemine Uygulanması
}

\author{
Abdullah Demir ${ }^{1, *}$, Ali Ersin Dinçer ${ }^{2}$ \\ ${ }^{1}$ Orta Doğu Teknik Üniversitesi, Mühendislik Fakültesi, Yapı Mekaniği Anabilim Dalı, 06800, Ankara. \\ 2Orta Doğu Teknik Üniversitesi, Mühendislik Fakültesi, Hidromekanik Anabilim Dalı, 06800, Ankara.

\section{Özet} \\ Aklşkan-yapı etkileșimi (fluid-structure interaction: FSI) çok uzun bir geçmișe sahip değildir. Araștırmacılar tarafindan akıșkan ve \\ yapı ayrı ayrı farklı formülasyonlar ile modellenmiştir. Fakat literatürdeki akışkan yapı etkileşimini inceleyen çalı̧̧malar sınırlı \\ sayıdadır ve bu çalışmalarda incelenen problemler çoğunlukla inşaat mühendisliği alanlarının dışında kalmıştır. Baraj yıkılmaları, \\ taşkının yapılara etkisi, çalkalanma etkisi ve tsunami gibi problemler inşaat mühendisliğindeki akışkan-yapı etkileşimini içeren \\ problemlerdir. Bu çalışmada, akışkan için "Moving Particle Semi-implicit (MPS)" metodu ve yapı için sonlu eleman metodu (finite \\ element method: FEM) kullanılarak bir akışkan-yapı etkileşim modeli geliştirilmiştir. Geliştirilen model idealize edilmiş ardıl baraj- \\ yıkılma problemine uygulanmıştır. Yıkılan üst barajın alt baraj gövdesindeki etkisi basınç okumaları ile gözlemlenmiştir. Bunun \\ yanında, alt baraj haznesindeki taşkın davranışı verilen su yüzeyi profilleri ile gözlemlenmiştir. Her iki sonuç da ileriye dönük \\ çalışmalar ve alınacak önlemler için kullanılabilir.
}

\section{Anahtar Sözcükler}

Akışkan-Yapı Etkileşimi, FSI, MPS, Kontak Mekanik, Ardıl Baraj-Yıkılma

\section{Application of MPS and FEM based Fluid-Structure Interaction Model to a Sequential Dam-Break Problem on Çoruh River}

\begin{abstract}
Studies about fluid-structure interaction (FSI) problems do not have a long history. Fluid and structure has been separately modelled with different formulations by researchers. However, studies about FSI are limited and problems investigated in these studies are mostly out of civil engineering areas. Problems such as dam-breaking, flood effect on structure, slushing effect and tsunami are the problems consisting of a fluid structure interaction in civil engineering. The present study, a fluid structure interaction model is developed by using moving particle semi-implicit method (MPS) and finite element method (FEM) for fluid and structure, respectively. The developed code is applied to an idealized sequential dam-break problem. The effect of failed upper dam on the lower dam body is investigated in terms of pressure readings. Besides, behavior of flood in lower reservoir is observed with given profiles of surface water. Both results can be used for future studies and taking protective measures.
\end{abstract}

$\underline{\text { Keywords }}$

Fluid-Structure Interaction, FSI, MPS, Contact Mechanics, Sequential Dam-Break

\section{Giriş}

Baraj yıkılmaları tasarım hataları, düşük kalitede malzeme kullanımı, doğal afetler, yetersiz bakım, insan ve bilgisayar hataları ve aşırı yağış gibi birçok farklı sebeplerden dolayı gerçekleşebilir. Tarihteki en büyük baraj felaketleri şöyle özetlenebilir; South Fork Baraj1 (1889), Tigra Baraj1 (1917), Kurenivka çamur-kayması (1961), Panshet Baraj1 (1961), Vajont Barajı (1963), Banqiao ve Shimantan Barajları (1975), Machchu-2 Baraj1 (1979). Yukarıdaki baraj felaketlerinden dolayı yaklaşık 200.000 insan hayatını kaybetmiştir. Yakın tarihlerdeki felaketler; Köprü Barajı (2012), Dakrong 3 Baraj1 (2012), Tokwe Mukorsi Baraj1 (2014) ve Germano maden barajlar1 (2015). Erken uyarı sistemleri ve gelişen teknoloji sayesinde baraj felaketlerinden dolayı hayatını kaybeden insan sayısı azımsanmayacak miktarda düşürülmüştür. Su seviyesi ve taşkın hızı tahminleri baraj felaketlerinden dolayı oluşacak zararları minimize eder. Literatürde taşkın simülasyonları için önerilen çeşitli numerik metotlar vardır. Bu çalışmada sadece akışkan davranışına değil aynı zamanda yapıya uygulanan kuvvetlere de odaklanılır.

1985'lerde kontak mekaniğin formülasyonu ile başlayan FSI (fluid-structure interaction), 30 yıllık bir geçmişe sahiptir. Kontak mekanikten önce ayrık cisimlerin etkileşimi bütünleşik bir şekilde yapılmamıştır. Akıșkan ve yapı gibi farklı ayrık yapıların bütünleşik çözümü günümüzde mümkündür ve FSI birçok araştırmacının ilgisini çekmektedir. 
FSI problemlerinde temel olarak, akışkan ve yapı, bir bütünleştirici mekanizma yardımı ile bütünleşik hale getirilir ve beraber çözülür. Bunun yanında, tanımlanan bütünleştirici mekanizma ve akışkanın ve yapının formülasyonu literatürdeki metotlarda değişiklik gösterir. Bathe (1999), Dowell (2001), Ohayon ve Felippa (2001) ile Tezduyar ve Bazilevs (2008) bunlardan birkaçıdır. Akışkan ve yapı modelleri için çeşitli metotlar geliştirilmiştir. Bu çalışmada, bir bütünleşik akışkan-yapı etkileşimi modeli sunulmuştur. Akışkan modeli için MPS (moving particle semi-implicit) metodu ve yapı modeli için sonlu eleman metodu (FEM) kullanılmıştır. Bütünleştirici mekanizma olarak ise kontak mekanik kullanılmıştır.

Bu çalışma, MPS ve FEM metotları için kısa tanımlar ile başlamaktadır. Sonrasında kontak mekanik için tanımlama ile devam etmektedir. İki ardıl baraj tanımlanan metot ile modellenmekte ve son olarak ardıl baraj yıkılmasının sonuçları verilmektedir.

\section{Nümerik Metotlar}

MPS metodu deterministik model bazlı eleman-tabansız (meshfree) bir metottur. Metotta, akışkan yerini bir takım parçacıklar alır ki bunlar akışkanın ana özelliklerini taşır ve kütle, momentum ve enerji denklemlerini takip eder. MPS metodu ilk olarak Koshizuka ve Oka (1996) tarafından geliştirilmiştir. Daha sonra metot farklı araştırmacılar tarafından geliştirilmiştir. Örneğin Khayyer ve Gotoh (2008; 2009) doğrulanmış MPS’yi sunmuşlardır. Metottaki geliştirmeler Khayyer ve Gotoh (2013), Hwang vd. (2014), Tanaka ve Masunaga (2010), Khayyer ve Gotoh (2011) tarafından sunulan çalışmalarda görülebilir.

Sıkışmaz akış için süreklilik ve Navier-Stokes denklemleri şunlardır:

$$
\begin{aligned}
& \frac{\partial \rho}{\partial \mathrm{t}}=0 \\
& \frac{\mathrm{D} \overrightarrow{\mathrm{u}}}{\mathrm{Dt}}=-\frac{1}{\rho} \nabla \mathrm{P}+\vartheta \nabla^{2} \overrightarrow{\mathrm{u}}+\overrightarrow{\mathrm{g}}
\end{aligned}
$$

Burada; $\rho$ akışkan yoğunluğu, t zaman, $\overrightarrow{\mathrm{u}}$ hız, $\mathrm{P}$ basınç, $\vartheta$ kinematik viskozite ve $\overrightarrow{\mathrm{g}}$ yerçekimsel ivmedir. Genel bir MPS kodundaki MPS denklemleri ve algoritması Koshizuka ve Oka (1996) tarafindan sunulan çalışmada bulunabilir. Bu çalışmada kullanılan MPS kodu, Koshizuka ve Oka (1996)'nın çalışmasında verilen denklemler ve algoritmalar kullanılarak geliştirilmiştir.

Çeşitli yapı problemlerini çözmek için kullanılan FEM yaygın olarak bilinen bir metottur. Araştırmacılar tarafından çok farklı notasyonlarda tanımlanmıştır. Bu çalışmada Bathe (1982) notasyonu kullanılmaktadır.

Kontak mekanik boşlukta farklı alanlara sahip farklı cisimleri etkileştirmek için kullanılan bir metottur. Temel formülasyonu Bathe ve Chaudary (1985) tarafından verilmiştir, ki bu çalışmada iki katı yapı etkileşimi vardır. MPS ile formüle edilmiş akışkan ve FEM ile formüle edilmiş yapı etkileşimi için Bathe ve Chaudary (1985) çalışması üzerinde bazı değişiklikler yapılır. Akışkan parçacıkları akışkan alanında MPS formülasyonlarına tabii olsa da, yapı alanını işgal eden akışkan parçacıklarının hareketleri için Newmark Metodu $(\alpha=0,5$ ve $\beta=0,25)$ kullanılır. Böylece akışkan parçacıklarından gelen bir ek $\frac{2}{\Delta \mathrm{t}^{2}} \mathrm{M}$ yapı rijitlik matrisine eklenir. Burada $\Delta$ t MPS'de kullanılan zaman aralığı ve M katı alanını işgal eden su parçacıklarının kütle matrisidir. Kontak rijitlik matrisini de içeren sistemin rijitlik matrisi çözüldüğünde her iki yapının (katı yapı ve akışkan parçacıkların) yer değiştirmeleri elde edilir.

$\mathrm{Bu}$ formülasyonların yanında, alan işgalinin tespiti için bir kontak arama algoritması kullanılır. İki boyutlu noktadoğru kontak (node to line contact) problemi olmasından dolayı, su parçacıklarından en yakın hedef yapı yüzeyindeki noktalara çizilen vektörlerin çapraz çarpımlarının işaretlerinin kıyaslanması kullanılır. Bu metot bilinen en basit kontak arama algoritmasidir.

\section{Model}

Irmaklarda birçok ardıl barajlar vardır. Bu çalışmada, Türkiye'deki Çoruh nehri üzerindeki HES'lerden esinlenilmiştir. Çoruh nehri ana kolu üzerinde 10 adet baraj bulunmaktadır. Bu barajların isimleri: Laleli, İspir, Güllübă̆, Aksu, Arkun, Yusufeli, Artvin, Deriner, Borçka ve Muratlı'dır. Ayrıca Çoruh nehrinin Oltu ve Berta kollarında dahi ardıl barajlar bulunmaktadır. Ana kol üzerindeki birkaç baraj Şekil 1'de sırasıyla görülebilir. Ardıl barajlardan birinin yıkılması tekil bir barajın yıkılmasından çok daha fazla zarara yol açacaktır. Bu çalışmada iki ardıl barajın idealize edilmiş bir modeli simüle edilmektedir. 


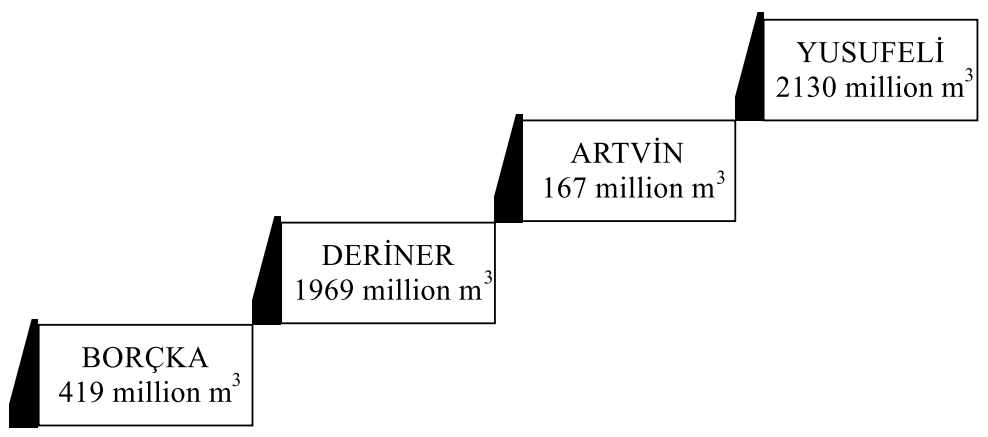

Şekil 1: Çoruh nehri ana kolu üzerindeki barajlar

Bu çalışmadaki nümerik hesaplamalar iki boyutludur. Numerik model Şekil 2'de görülebilir. Simülasyonlarda üst barajın aniden yıkıldığı varsayılmaktadır. Her iki baraj da aynı boyutlarda modellenmiştir ve baraj haznesinin boyu baraj gövdesi yüksekliğinin on katı olarak alınır. MPS modelinde 2500 su parçacığı kullanılır. Parçacıklar arasındaki ilk boşluk 0,001m olarak alınır. MPS metodunun sınır koşulları kontak mekanik ile sağlanır. Nehir yatağı sınırı ve baraj gövdesi sınırı FEM ile modellenir. Nehir yatağı için her noktasından mesnetlenmiş basit bir eleman modeli kullanılır. Buna karşın, baraj gövdesi 50 adet düzlem gerinim elemanı ile modellenir ve baraj gövdesi modeli sadece nehir yatağında mesnetlenir. Bu çalışmada, basınçlara ek olarak yer değiştirmeler de hesaplanır. Alt baraj gövdesinin yıkılmayacağı varsayıldığı ve baraj gövdesindeki yer değiştirmelerin taşkında değişiklik yaratmayacağı bilindiği için hesaplanan yer değiştirmeler verilmez.

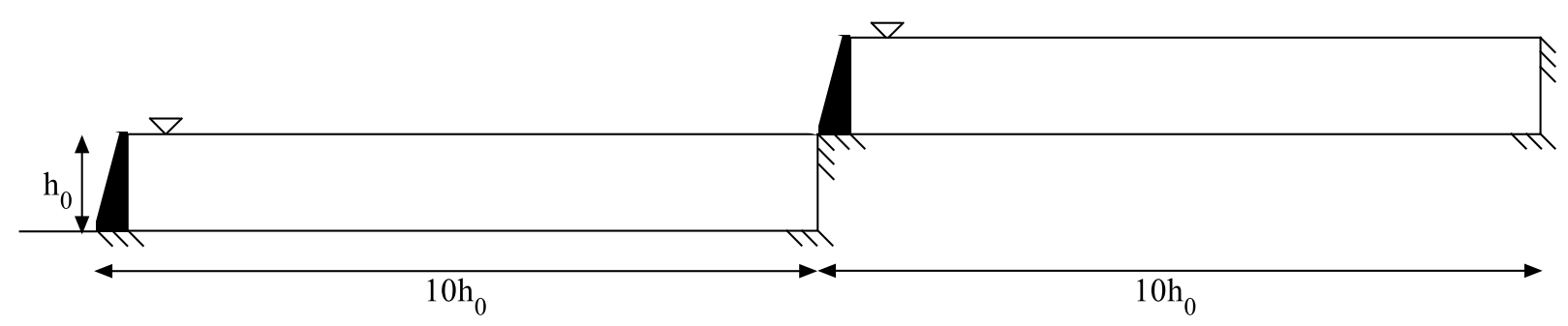

Şekil 2: Numerik model

\section{Analiz Sonuçları}

Nümerik sonuçlar boyutsuz olarak verilir. Boyutsuz uzunluk, zaman ve basınç sırasıyla $H=h / h_{0}, T=t \sqrt{g_{0}}$, $\mathrm{P}=\mathrm{p} / \rho \mathrm{gh}_{0}$ eşitlikleri ile hesaplanır.

Üst barajın yıkılmasından sonraki her $\mathrm{T}=0,303$ boyutsuz zamandaki su yüzeyi profilleri Şekil 3 'te görülebilir. Numerik çözümün idealize edilmiş olmasından dolayı, şekil suyun dolu bir kaba boşalmasına benzerdir. Yıkılmadan dolayı oluşan dalgaların ilerleyişi Şekil 3'te takip edilebilir. Yıkılan barajdan boşalan suyun oluşturduğu dalganın başlangıç genliği alt baraj gövdesi yüksekliğinin \%20'sidir. Taşkın, alt barajın yıkılmayacağı varsayımı ile boşalır. Şu bilinen bir gerçektir ki; barajlarda dolu savak ve dip savak gibi önleyici sistemler bulunmaktadır. Fakat FSI simülasyonları ve sonuçlarına odaklanmak adına hiçbir önleyici sistem uygulanmaz ve barajın yıkılacağı gerçeği bu çalışmada göz önüne alınmaz. İlk dalganın genliği alt baraj gövdesine yaklaştıkça baraj gövdesinin \%10’una kadar düşmektedir. Bir süre sonra tek bir taşkın dalgası yerine sabit bir hazne yüksekliği gözlemlenir. 


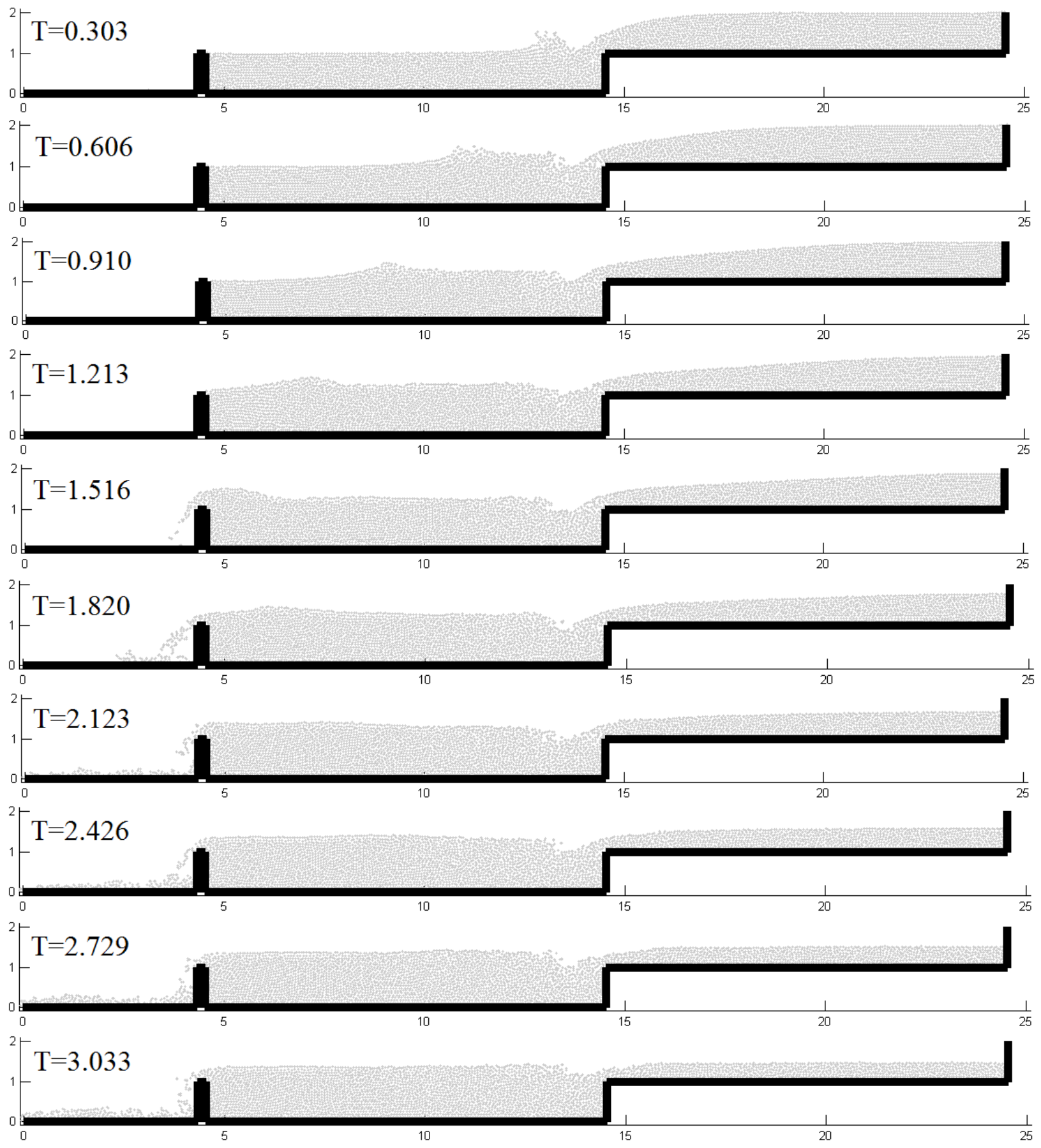

Şekil 3: Taşkın boyunca su yüzeyi profilleri

Şekil 4'te gri ve siyah sürekli çizgiler ile basınç okumaları gösterilmiştir. Gri çizgi MPS sonucundan hesaplanan basınçlar, siyah çizgi FSI sonuçlarından hesaplanan basınçlardır. Basınçlar MPS'de baraj gövdesinin orta noktasına en yakın parçacık basınçlarından hesaplanır. Buna karşın FSI'da basınçlar baraj gövdesini işgal eden su parçacıklarının çıkarılması için gereken kuvvetlerden hesaplanır. Alt barajın orta noktasındaki basıncın zamana bağlı değişimi Şekil 4'de görülebilir. Grafiğin başlangıcında basınçtaki artış ve dalgalanmalar tanımlanan su parçacıklarının ilk çarpma etkisidir. Bundan dolayı başlangıçtaki basınç artışı göz ardı edilmelidir. Taşkından dolayı basınçta beklenen ana artış $\mathrm{T}=1,5$ 'te gözlemlenir. Nümerik simülasyondan dolayı grafikte dalgalanmalar olmasına rağmen, ortalama basınç yaklaşık olarak $\mathrm{P}=0,5$ olarak okunabilir. Taşkın alt baraja ulaştığı anda basınçta yaklaşık \% 75 'lik bir artış gözlemlenir. Bunun yanında, basınç dalgalanmalarının genliği de artar. 


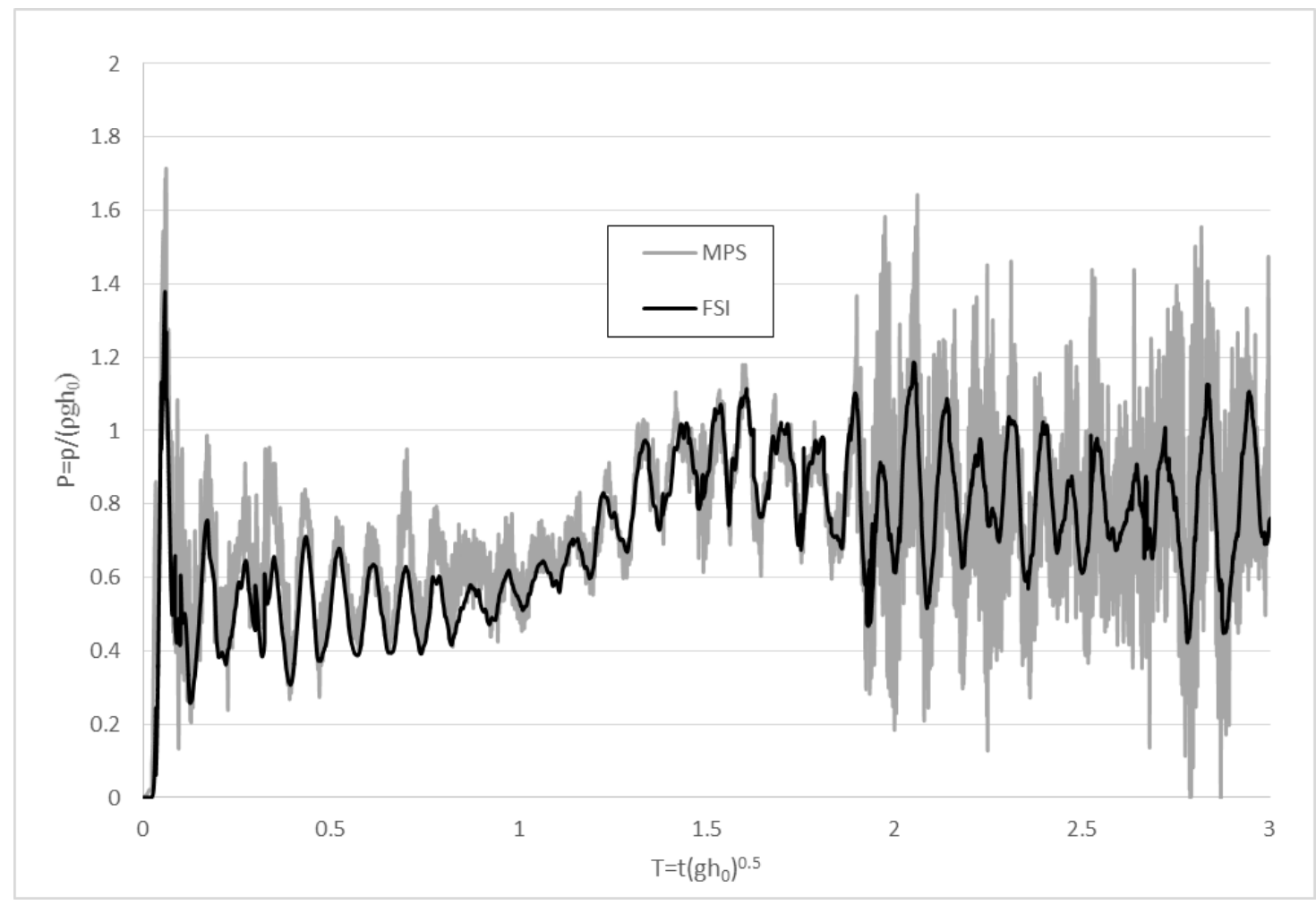

Şekil 4: Alt barajın orta noktasında hesaplanan basınçlar

\section{Sonuç ve Tartışma}

Bu çalışmada ardıl bir baraj yıkılma probleminin FSI çözümü, MPS ve FEM ile gerçekleştirilmiştir. Model, Türkiye'de bulunan Çoruh Nehri üzerindeki ardıl barajların çokluğundan esinlenerek hazırlanmıştır. Çoruh nehri üzerinde 10 adet yüksek kapasiteli baraj bulunmaktadır. Bu barajlar büyük güvenlik katsayıları ile tasarlanmış olsa da herhangi bir barajdaki yıkılmanın diğer barajlara olan etkisi tasarımlarda yalnızca kapasite artışı olarak göz önüne alınmıştır. Muhtemel bir ardıl baraj yıkılması, gerek barajlar arasındaki mesafe gerek her bir barajın kapasitesine bağlı olsa da yapılan bu çalışma ardıl baraj yıkılmalarının etkisini gözler önüne seren örnek tip bir çalışmadır. Şekil 3'te görüldüğü gibi baraj yıkılmasından sonra oluşan dalga genliği baraj gövdesi yüksekliğinin \%20'si kadardır. Bu dalga mansaptaki baraj gövdesine ulaşınca genliğinin \%50'sini kaybeder. Bu kaybın mansaptaki barajın kapasitesi ile doğru orantılı olacağı düşünülmektedir. Buna ek olarak Şekil 4'te görüleceği gibi üst barajın yıkılmasından dolayı oluşan taşkınla alt barajda \% 75'lik bir basınç artışı gözlemlenmiştir. Bu artış daha sonra \%20’lik bir kayıpla çalkalanma seyrini almıştır. Taşkından dolayı sediment taşınması artar ki bu baraj gövdesindeki basıncı daha da artıracaktır. Fakat bu etki bu çalışmada göz ardı edilmiştir. Çünkü bu etkinin hesaplanabilmesi için gerekli hiçbir çalışma bulunmamaktadır. Bunun yanında bu çalışmada her iki baraj haznesinin de dolu olduğu varsayılmıştır. Böyle olmakla beraber, ileride, hazne su seviyelerinin ve haznelerin birbirinden uzaklıklarının değiştiği ve sediment etkisinin göz önüne alındığı daha kapsamlı bir çalışma gerçekleştirilebilir.

\section{Kaynaklar}

Bathe K.J., (1982), Finite element procedures in engineering analysis, Prentice-Hall, Englewood Cliffs, New Jersey, USA, 735ss.

Bathe K.J., Chaudhary A., (1985), A solution method for planar and axisymmetric contact problems, International Journal for Numerical Methods in Engineering, 21, 65-88.

Bathe K.J., Zhang H., Ji S., (1999), Finite element analysis of fluid flows fully coupled with structural interactions, Computers \& Structures, 72(1-3), 1-16.

Dowell E.H., Hall K.C., (2001), Modeling of fluid-structure interaction, Annu. Rev. Fluid Mech., 33(1), 445-490.

Hwang S., Khayyer A., Gotoh H., Park J., (2014), Development of a fully lagrangian MPS-base coupled method for simulation of fluid-structure interaction problems, J. Fluids Struct., 50, 497-511.

Khayyer A., Gotoh H., (2008), Development of CMPS method for accurate water-surface tracking in breaking waves, Coast. Eng. J., 50(2), 179-207.

Khayyer A., Gotoh H., (2009), Modified moving particle semi-implicit methods for the prediction of $2 d$ wave impact pressure, Coast. Eng., 56(4), 419-440. 
Khayyer A., Gotoh H., (2011), Enhancement of stability and accuracy of the moving particle semi-implicit method, J. Comput. Phys., 230(8), 3093-3118.

Khayyer A., Gotoh H., (2013), Enhancement of performance and stability of MPS mesh-free particle method for multiphase flows characterized by high density ratios, J. Comput. Phys., 242, 211-233.

Koshizuka S., Oka Y., (1996), Moving particle semi-implicit method or fragmentation of incompressible fluid, Nucl. Sci. Eng., 123, 421-434.

Ohayon R., Felippa C.E., (2001), Advances in computational methods for fluid-structure interaction and coupled problems, Comput. Methods Appl. Mech. Eng., 190, 2977-3292.

Tanaka M., Masunaga T., (2010), Stabilization and smoothing pressure in MPS method by quasi-compressibility, J. Comput. Phys., 229(11), 4279-4290.

Tezduyar T., Bazilevs Y., (2008), Fluid-structure interaction, Comput. Mech., 43, 1-189. 